\title{
Retraction Note to: Various Kinds of Bone Disease in Diabetes: Rheumatic Conditions
}

\author{
Hitoshi Goto
}

(C) Springer Japan 2016

M. Inaba (ed.), Musculoskeletal Disease Associated with Diabetes Mellitus, DOI 10.1007/978-4-431-55720-3_2

The chapter published in Musculoskeletal Disease Associated with Diabetes Mellitus, pages 11-25, 10.1007/978-4-431-55720-3_2 has been retracted because it contains significant parts plagiarizing another publication: Rheumatic conditions in patients with diabetes mellitus, Clinical Rheumatology, Volume 32, Issue 5, pages 527-533, 10.1007/s10067-012-2144-8. The authors would like to express their most sincere apology to the Editor and readers as well as the authors of the original article.

The online version of the original chapter can be found at http://dx.doi.org/10.1007/978-4-431-55720-3_2

H. Goto, M.D. ( $₫)$

Graduate School of Medicine, Osaka City University, 1-4-3, Asahi-machi, Abeno-ku, Osaka 545-8585, Japan

e-mail: goto@msic.med.osaka-cu.ac.jp 